\title{
EVALUASI PENERAPAN PPH PASAL 22 ATAS PEMBELIAN BARANG YANG DIBIAYAI DENGAN APBN DI PENGADILAN TATA USAHA NEGARA MANADO
}

\author{
Maria Angelitha Mapanawang ${ }^{1}$, Jullie Sondakh², Rudy Pusung ${ }^{3}$ \\ 1,2,3 Jurusan Akuntansi, Fakultas Ekonomi dan Bisnis, Universitas Sam Ratulangi, Jl. Kampus Bahu, Manado, \\ 95115, Indonesia \\ E-mail: maria_angelitha@yahoo.com
}

\begin{abstract}
Each country has several sources of tax revenue, non-tax revenues and grants. From these sources of income, the tax becomes one. This research is intended to find out and apply whether Article 22 Income Tax on the purchase of goods financed by APBN in Manado State Administrative Court has been implemented in accordance with the established rules, namely Regulation of the Minister of Finance of the Republic of Indonesia Number 107/PMK.010/2015 and PMK 242/PMK.03/2014. Period of data taken is 2016. Type of research used is descriptive which will discuss about the implemeniation of Article 22 Income Tax on the purchase of goods financed by the State Budget at the State Administrative Court of Manado. The type of data used is qualitative data proof SSP PPh Article 22. The results of this study indicate Calculation, Payment, and Reporting on the procurement of goods financed by the state budget at the State Administrative Court of Manado not in accordance with the rules it stipulates from the application of Manado State Administrative Court Record has been in accordance with existing regulations.
\end{abstract}

Keywords : calculation, registration, payment, reporting, article 22 income tax

\section{PENDAHULUAN}

Setiap negara memiliki beberapa sumber pendapatan, yaitu penerimaan perpajakan, penerimaan bukan pajak dan hibah. Dari sumber-sumber pendapatan tersebut, pajak menjadi salah satu pendapatan terbanyak suatu negara.

Di Indonesia, pengenaan pajak dapat dikelompokkan menjadi 2 (dua) bagian, yaitu pajak negara dan pajak daerah.

Pajak negara, yang terdiri dari:

1. Pajak Penghasilan (PPh)

2. Pajak Pertambahan Nilai dan Pajak Penjualan Atas Barang Mewah (PPN \& PPn BM)

3. Bea Meterai

4. Pajak Bumi dan Bangunan (PBB)

5. Bea Perolehan Hak Atas Tanah dan Bangunan (BPHTB)

Pajak Daerah, yang dibagi dua bagian, yaitu:

1. Pajak Provinsi, yang terdiri dari:
a. Pajak Kendaraan Bermotor
b. Bea Balik Nama Kendaraan Bermotor
c. Pajak Bahan Bakar Kendaraan Bermotor
d. Pajak Air Permukaan
e. Pajak Rokok

2. Pajak Kabupaten/Kota, yang terdiri dari:
a. Pajak Hotel
b. Pajak Restoran
c. Pajak Hiburan 

d. Pajak Reklame
e. Pajak Penerangan Jalan
f. Pajak Mineral Bukan Logam dan Batuan
g. Pajak Parkir
h. Pajak Air Tanah
i. Pajak Sarang Burung Walet
j. Pajak Bumi dan Bangunan Pedesaan dan Perkotaan
k. Bea Perolehan Hak Atas Tanah dan Bangunan

Salah satu jenis pajak yang ditetapkan oleh pemerintah yang sangat menarik dan penting adalah Pajak Penghasilan. Pajak Penghasilan yaitu pajak negara yang dikenakan terhadap setiap tambahan kemampuan ekonomis yang diterima atau diperoleh Wajib Pajak, baik yang berasal dari dalam Indonesia maupun yang berasal dari luar Indonesia, yang tujuannya untuk konsumsi atau untuk menambah kekayaan dari Wajib Pajak yang bersangkutan.

Ada beberapa jenis-jenis pajak penghasilan, yaitu:

1. Pajak Penghasilan Pasal 21

2. Pajak Penghasilan Pasal 22

3. Pajak Penghasilan Pasal 23

4. Pajak Penghasilan Pasal 24

5. Pajak Penghasilan Pasal 25

6. Pajak Penghasilan Pasal 4 ayat 2

Pajak Penghasilan Pasal 22 merupakan pembayaran Pajak Penghasilan dalam tahun berjalan yang dipungut oleh bendahara pemerintah, termasuk bendahara pemerintah pusat, pemerintah daerah, instansi atau lembaga pemerintah, dan lembaga negara lainnya, yaitu berkenaan dengan pembayaran atas penyerahan barang, termasuk juga dalam pengertian bahwa bendahara adalah berkewajiban sebagai pemegang kas dan pejabat lainnya menjalankan fungsi yang sama.

Sebagai pemungut pajak adalah Direktorat Jendral Perbendaharaan, Bendahara Pemerintah baik yang ada di tingkat pusat ataupun di tingkat daerah, yang melakukan pembayaran atas pembelian barang. Dan yang merupakan objek pemungutan $\mathrm{PPh}$ pasal 22 adalah pembayaran atas pembelian barang yang dilakukan oleh Badan Usaha Milik Negara dan Badan Usaha Milik Daerah yang dananya berasal dari belanja negara atau belanja daerah.

Sebagai pemungut pajak bisa terjadi kesalahan atau kekeliruan dalam penerapan perhitungan, pencatatan, pembayaran dan pelaporan PPh Pasal 22 yang telah dipungut sehingga bisa berpengaruh terhadap kerugian pendapatan perpajakan dan rekanan. Oleh sebab itu, sangat diperlukan pemahaman yang baik dan teliti pada penerapan perhitungan, pencatatan, pembayaran dan pelaporan PPh Pasal 22 tersebut. Penelitian ini akan dilakukan di Pengadilan Tata Usaha Negera Manado. Penerapan PPh Pasal 22 yang dilakukan oleh Pengadilan Tata Usaha Negara Manado ini yaitu berkaitan dengan evaluasi penerapan perhitungan, pencatatan, pembayaran dan pelaporan terhadap pengadaan barang seperti pembelian dan tidak mengadakan penjualan dan pembelian impor dan menggunakan anggaran belanja negara atau belanja daerah yang berlaku di tahun 2016.

Dengan memperhatikan alasan dan keterangan di atas, penelitian ini akan membahas tentang penerapan PPh Pasal 22 yang berupa perhitungan, pencatatan, pembayaran dan pelaporan PPh Pasal 22 atas pembelian barang yang dibiayai dengan APBN di Pengadilan Tata Usaha Negara Manado, sebagaimana dengan yang diatur dalam Pasal 22 UndangUndang PPh, Peraturan Menteri Keuangan Nomor 154/PMK.03/2010 sebagaimana telah diubah terakhir dengan Peraturan Menteri Keuangan Republik Indonesia Nomor 107/PMK.010/2015 dan PMK 242/PMK.03/2014. 


\section{TINJAUAN PUSTAKA}

\subsection{Konsep Akuntansi}

Pengertian akuntansi adalah seperangkat pengetahuan yang mempelajari perekayasaan dalam penyediaan jasa, yang berupa informasi keuangan kuantitatif dari suatu unit organisasi dan cara penyampaian (pelaporan) informasi tersebut kepada pihak yang berkepentingan untuk dijadikan dasar pengambilan keputusan ekonomi. (Pura, 2013:4)

\subsection{Konsep Pajak}

Pajak adalah iuran masyarakat kepada negara (yang dapat dipaksakan) yang terutang oleh yang wajib membayarnya menurut peraturan-peraturan umum (undang-undang) dengan tidak mendapat prestasi kembali yang langsung dapat ditunjukkan dan yang gunanya adalah untuk membiayai pengeluaran-pengeluaran umum berhubung tugas negara untuk menyelenggarakan pemerintahan. (Sumarsan, 2015:3)

Pajak juga sebagai suatu kewajiban menyerahkan sebagian dari kekayaan ke kas negara yang disebabkan suatu keadaan, kejadian, dan perbuatan yang memberikan kedudukan tertentu, tetapi bukan sebagai hukuman, menurut peraturan yang ditetapkan pemerintah serta dapat dipaksakan, tetapi tidak ada jasa timbal balik dari negara secara langsung, untuk memelihara kesejahteraan secara umum. (Resmi, 2013: 1)

\subsection{Pajak Penghasilan}

Pajak penghasilan dikenakan terhadap subjek pajak atas penghasilan yang diterima atau diperolehnya dalam tahun pajak. Yang menjadi Subjek Pajak adalah:

1. a. Orang pribadi

b. Warisan yang belum terbagi sebagai satu kesatuan menggantikan yang berhak

2. Badan, terdiri dari perseroan terbatas, perseroan komanditer, perseroan lainnya, BUMN/BUMD dengan nama dan bentuk apapun, firma, kongsi, koperasi, dana pension, perse-kutuan, perkumpulan, yayasan,organisasi social politik, atau organisasi lainnya, lembaga, dan bentuk badan lainnya termasuk kontrak investasi kolektif.

3. Bentuk Usaha Tetap.(BUT)

\subsection{Pajak Penghasilan Pasal 22}

Pajak penghasilan pasal 22 merupakan pembayaran pajak penghasilan dalam tahun berjalan yang dipungut oleh:

1. Bendahara pemerintah, termasuk bendahara pada pemerintah pusat, pemerintah daerah, instansi atau lembaga pemerintah, dan lembaga-lembaga negara lainnya, berkenaan dengan pembayaran atas penyerahan barang, termasuk juga dalam pengertian bendahara adalah pemegang kas dan pejabat lain yang menjalankan fungsi sama

2. Badan-badan tertentu, baik badan pemerintah maupun swasta, berkenaan dengan kegiatan di bidang impor atau kegiatan usaha di bidang lain, seperti kegiatan usaha produksi barang tertentu antara lain otomotif dan semen

3. Wajib Pajak badan tertentu untuk memungut pajak dari pembeli atas penjualan barang yang tergolong sangat mewah. Pemungut pajak oleh Wajib Pajak badan tertentu ini akan dikenakan terhadap pembelian barang yang memenuhi kriteria tertentu sebagai barang yang tergolong sangat mewah baik dilihat dari jenis barangnya maupun harganya, seperti kapal pesiar, rumah sangat mewah, apartemen dan kondominium sangat mewah, serta kendaraan sangat mewah

\subsection{PPh Pasal 22 Atas Pembelian Barang yang Dibiayai Oleh APBN/APBD}

\section{Perhitungan PPh Pasal 22 atas Pembelian Barang yang Dibiayai Dengan APBN}

Dalam hal melakukan perhitungan PPh Pasal 22 yang dibiayai dengan APBN besarnya

pungutan yaitu: Atas pembelian barang sebagaimana dimaksud dalam Pasal 1 ayat (1) huruf $\mathrm{b}$, huruf c, huruf d, dan pembelian barang dan/atau bahan-bahan untuk keperluan kegiatan usaha sebagaimana dimaksud dalam Pasal 1 ayat (1) huruf e, sebesar 1,5\% (satu koma lima 
persen) dari harga pembelian tidak termasuk Pajak Pertambahan Nilai (Peraturan Menteri Keuangan Republik Indonesia No. 107/PMK.010/2015)

Pemungutan PPh Pasal 22 atas belanja barang tidak dilakukan dalam hal :

1. Pembelian barang dengan nilai pembelian paling banyak Rp. 2.000.000,00 (dua juta rupiah) dengan tidak dipecah-pecah dalam beberapa faktur.

2. Pembelian bahan bakar minyak, listrik, gas, pelumas, air minum/PDAM dan bendabenda pos

3. Pembayaran untuk pembelian barang sehubungan dengan penggunaan Bantuan Operasional Sekolah (BOS)

Pengertian nilai pembelian tidak dipecah-pecah adalah nilai satu transaksi pembelian tersebut tidak dipecah-pecah dalam beberapa tagihan atau faktur sehingga seolah-olah menjadi beberapa transaksi yang terpisah dengan nilai yang tidak melebihi Rp. 2.000.000 (dua juta rupiah). Dalam hal terjadi pemecahan nilai pembelian atas suatu transaksi yang menjadi satu kesatuan tersebut, walaupun nilai transaksi pembelian yang terpisah kurang dari $\mathrm{Rp}$. 2.000.000 (dua juta rupiah) namun tetap dilakukan pemungutan PPh Pasak 22. Pengaturan ini dimaksudkan agar pihak Wajib Pajak tidak menempuh upaya untuk menghindari PPh Pasal 22. (Direktorat Jendral Pajak, 2016:15)

\section{Pencatatan PPh Pasal 22 Atas Pembelian Barang yang Dibiayai dengan APBN}

Pembukuan terhadap seluruh penerimaan dan pengeluaran sebagaimana diatur pada ayat (1) dilakukan dengan aplikasi yang dibuat dan dibangun oleh Kementerian Keuangan atau Direktorat Jenderal Perbendaharaan. (Peraturan Direktur Jenderal Perbendaharaan Nomor PER-3/PB/2014)

\section{METODE PENELITIAN}

\subsection{Jenis Penelitian}

Jenis penelitian ini adalah deskriptif dimana akan membahas tentang evaluasi penerapan PPh Pasal 22 atas pembelian barang yang dibiayai dengan APBN di Pengadilan Tata Usaha Negara Manado. Jenis penelitian deskriptif yaitu metode pembahasan, permasalahan yang didalamnya bersifat menguraikan, menggambarkan suatu keadaan atau data untuk menerangkan suatu keadaan atau fenomena sedemikian rupa dapat dihasilkan kesimpulan untuk menjawab permasalahan yang ada.

\subsection{Metode Pengumpulan Data}

\section{Jenis Data}

Data adalah kumpulan informasi yang diperoleh dari suatu pengamatan, dapat berupa angka, lambang atau berdasarkan sifatnya. Menurut sifatnya, jenis-jenis data yaitu:

1. Data kualitatif, yaitu data yang tidak berbentuk angka

2. Data kuantitatif, yaitu data yang berbentuk angka

Jenis data yang digunakan dalam penelitian ini adalah data kualitatif berupa bukti SSP $\mathrm{PPh}$ Pasal 22.

\section{Sumber Data}

Sumber data yang dilakukan dalam penelitian ini adalah data primer dan data sekunder. Data primer dilakukan berupa observasi dan wawancara secara langsung dengan pihak-pihak yang berada di tempat penelitian di Pengadilan Tata Usaha Negara Manado. Sedangkan data sekunder diperoleh dari studi dokumentasi yang berupa mempelajari di berbagai buku, jurnal, internet dan skripsi-skripsi terdahulu yang membahas tentang PPh Pasal 22 


\section{HASIL PENELITIAN DAN PEMBAHASAN}

\subsection{Hasil Penelitian}

Penerapan Perhitungan PPh Pasal 22 atas Pembelian Barang yang Dibiayai dengan APBN di Pengadilan Tata Usaha Negara Manado

Perhitungan PPh Pasal 22 yang dilakukan oleh Pengadilan Tata Usaha Negara Manado sebagimana telah diatur dalam Peraturan Menteri Keuangan Republik Indonesia Nomor 107/PMK.010/2015 Pasal 2 ayat 1 huruf b yaitu harus sebesar 1,5\% dari harga pembelian tidak termasuk PPN. Dan dalam perhitungan terhadap PPh Pasal 22 atas belanja barang tidak dilakukan dalam hal pembelian barang dengan nilai pembelian paling banyak Rp. 2.000.000,(dua juta rupiah) dengan tidak dipecah-pecah dalam beberapa faktur.

Dalam tahun anggaran 2016 bulan Januari sampai dengan bulan Mei Pengadilan Tata Usaha Negara Manado tidak mengadakan pembelian barang yang mengharuskan Pengadilan Tata Usaha Manado untuk melakukan pemungutan PPh Pasal 22, pembelian barang yang dibiayai APBN dimulai pada bulan Juni dan pada bulan Juli kembali tidak mengadakan pembelian barang yang diharuskan untuk melakukan pemungutan PPh Pasal 22. Kemudian pengadaan barang dimulai kembali di bulan Agustus sampai dengan akhir tahun anggaran yaitu bulan Desember. Berikut ini adalah data perhitungan PPh Pasal 22 di Pengadilan Tata Usaha Negara Manado

Tabel 4.1 Pajak Penghasilan Pasal 22 Tahun Anggaran 2016 Pengadilan Tata Usaha Negara Manado.

\begin{tabular}{|c|c|c|c|c|}
\hline No. & Bulan & Objek PPh Pasal 22 & Harga Pembelian & $\begin{array}{c}\text { PPh Pasal } 22 \\
\text { Tarif } 1,5 \%\end{array}$ \\
\hline 1. & Januari & - & - & - \\
\hline 2. & Februari & - & - & - \\
\hline 3. & Maret & - & - & - \\
\hline 4. & April & - & - & - \\
\hline 5. & Mei & - & - & - \\
\hline \multirow[t]{2}{*}{6.} & Juni & AC Split & 25.000 .000 & 375.000 \\
\hline & & Meubeler & 167.450 .000 & 2.550 .000 \\
\hline 7. & Juli & - & - & - \\
\hline 8. & Agustus & Alat Pengelola Data & 95.800 .000 & 1.437 .000 \\
\hline 9. & Septermber & Bahan Bangunan & 11.770 .000 & 160.000 \\
\hline \multirow[t]{2}{*}{10.} & Oktober & Acer Touch Screen & 10.760 .000 & 197.925 \\
\hline & & Acer Touch Screen & 13.195 .000 & 161.400 \\
\hline \multirow[t]{3}{*}{11.} & November & Mixer Yamaha & 7.475 .000 & 112.125 \\
\hline & & Mic Shure & 1.980 .000 & 29.700 \\
\hline & & Anjungan Kios & 2.200 .000 & 33.000 \\
\hline 12. & Desember & Alat Tulis Kantor & 16.537 .500 & 248.063 \\
\hline
\end{tabular}

(sumber : PTUN MANADO, 2016)

Penerapan Pencatatan PPh Pasal 22 atas Pembelian Barang yang Dibiayai dengan APBN di Pengadilan Tata Usaha Negara Manado

Pencatatan PPh Pasal 22 atas pembelian barang yang dibiayai dengan APBN sesuai dengan Peraturan Direktur Jenderal Pajak Nomor PER-3/PB/2014 terhadap seluruh penerimaan dan pengeluaran dilakukan dengan aplikasi yang dibuat dan dibangun oleh Kementrian Keuangan atau Direktorat Jenderal Perbendaharaan. Dan pencatatan yang dilakukan oleh Pengadilan Tata Usaha Negara Manado dilakukan dengan menggunakan aplikasi SAS (Sistem Aplikasi Satker) yang dimana pencatatannya ditujukan untuk satker dan Kementrian Keuangan 
Berikut ini adalah tabel yang menyajikan pencatatan terhadap pemungutan $\mathrm{PPh}$ Pasal 22 atas pembelian barang yang dibiayai dengan APBN yang dilakukan oleh Pengadilan Tata Usaha Negara Manado:

Tabel 4.2 Pencatatan Terhadap Pemungutan PPh Pasal 22 yang dilakukan oleh Pengadilan Tata Usaha Negara Manado
No.
Bulan
Objek PPh Pasal
Debit
Kredit

22

\begin{tabular}{|c|c|c|c|c|}
\hline 1. & Januari & - & - & - \\
\hline 2. & Februari & - & - & - \\
\hline 3. & Maret & - & - & - \\
\hline 4. & April & - & - & - \\
\hline 5. & Mei & - & - & - \\
\hline \multirow[t]{2}{*}{6.} & Juni & AC Split & 375.000 & - \\
\hline & & Meubeler & 2.550 .000 & - \\
\hline 7. & Juli & - & - & - \\
\hline 8. & Agustus & $\begin{array}{c}\text { Alat Pengelola } \\
\text { Data }\end{array}$ & 1.437 .000 & - \\
\hline 9. & Septermber & Bahan Bangunan & 160.000 & - \\
\hline \multirow[t]{2}{*}{10.} & Oktober & Acer Touch Screen & 197.925 & - \\
\hline & & Acer Touch Screen & 161.400 & - \\
\hline \multirow[t]{3}{*}{11.} & November & Mixer Yamaha & 112.125 & - \\
\hline & & Mic Shure & 29.700 & - \\
\hline & & Anjungan Kios & 33.000 & - \\
\hline 12. & Desember & Alat Tulis Kantor & 248.063 & - \\
\hline
\end{tabular}

(sumber : PTUN MANADO, 2016)

Tabel 4.3 Pencatatan Terhadap Penyetoran PPh Pasal 22 yang dilakukan oleh Pengadilan Tata Usaha Negara Manado

\begin{tabular}{ccccc}
\hline No. & Bulan & Objek PPh Pasal 22 & Debit & Kredit \\
\hline 1. & Januari & - & - & - \\
\hline 2. & Februari & - & - & - \\
\hline 3. & Maret & - & - & - \\
\hline 4. & April & - & - & - \\
\hline 5. & Mei & - & - & 375.000 \\
\hline 6. & Juni & AC Split & & 2.550 .000 \\
\hline & & Meubeler & - & - \\
\hline 7. & Juli & - & - & 1.437 .000 \\
\hline 8. & Agustus & Alat Pengelola & - & 160.000 \\
\hline 9. & Septermber & Dahan Bangunan & - & 197.925 \\
\hline 10. & Oktober & Acer Touch Screen & - & 161.400 \\
\hline & & Acer Touch Screen & - & 112.125 \\
\hline 11. & November & Mixer Yamaha & - & 29.700 \\
\hline & & Mic Shure & - & 33.000 \\
\cline { 2 - 5 } & & Anjungan Kios & - & 248.063
\end{tabular}

(sumber : PTUN MANADO, 2016) 


\subsection{Pembahasan}

Evaluasi Penerapan Perhitungan PPh Pasal 22 atas Pembelian Barang yang Dibiayai dengan APBN di Pengadilan Tata Usaha Negara Manado

Dari hasil penelitian diatas peneliti mendapati bahwa penerapan perhitungan $\mathrm{PPh}$ Pasal 22 atas pembelian barang yang dibiayai dengan APBN di Pengadilan Tata Usaha Negara Manado pada (tabel 4.1) ada yang tidak sesuai dengan Peraturan Menteri Keuangan Republik Indonesia Nomor 107/PMK.010/2015 yaitu pada bulan November ketika terjadi pembelian barang Mic Shure dengan harga barang Rp. 1.980.000. Karena pada pembelian Mic Shure harga barangnya kurang dari Rp. 2.000.000,00 jadi seharusnya tidak dipungut PPh Pasal 22. Selain dari pembelian Mic Shure, penerapan perhitungan PPh Pasal 22 yang dilakukan oleh Pengadilan Tata Usaha Negara Manado telah sesuai dengan Peraturan Menteri Keuangan Republik Indonesia Nomor 107/PMK.010/2015 yaitu 1,5\% x harga beli (tidak termasuk PPN) dan pembelian barang dengan nilai pembelian paling banyak $\mathrm{Rp}$. 2.000.000,00 (dua juta rupiah) dengan tidak dipecah-pecah dalam beberapa faktur.

Evaluasi Penerapan Pencatatan PPh Pasal 22 atas Pembelian Barang yang Dibiayai dengan APBN di Pengadilan Tata Usaha Negara Manado

Penerapan pencatatan PPh Pasal 22 atas pembelian barang yang dibiayai dengan APBN di Pengadilan Tata Usaha Negara Manado telah berjalan dengan baik karena menggunakan aplikasi dari pemerintah yaitu SAS (Sistem Akrual Satker) dan pencatatan yang dilakukan oleh Pengadilan Tata Usaha Negara Manado ditujukan langsung ke Kementerian Keuangan dan satker sesuai dengan Peraturan Direktur Jenderal Perbendaharaan Nomor PER-3/PB/2014.

\section{PENUTUP}

\subsection{Kesimpulan}

Berdasarkan hasil penelitian dapat disimpulkan bahwa:

1. Sesuai dengan Peraturan Menteri Keuangan Republik Indonesia Nomor 107/PMK.010/2015, penerapan perhitungan PPh Pasal 22 atas pembelian barang yang dibiayai dengan APBN di Pengadilan Tata Usaha Negara Manado belum sesuai dengan ketentuan perpajakan yang berlaku. Hal ini terbukti dengan adanya perhitungan yang tidak seharusnya dipungut karena harga barangnya kurang dari Rp.2.000.000,00

2. Penerapan pembayaran $\mathrm{PPh}$ Pasal 22 atas pembelian barang yang dbiayai dengan APBN di Pengadilan Tata Usaha Negara Manado belum sesuai dengan Peraturan Menteri Keuangan Republik Indonesia Nomor 107/PMK.010/2015 dikarenakan Pengadilan Tata Usaha Negara Manado tidak membayarkan langsung PPh Pasal 22 yang telah dipungut pada hari yang sama setelah pembelian barang.

\subsection{Saran}

Berdasarkan kesimpulan yang telah dilakukan, adapun saran yang ingin peneliti sampaikan yaitu:

1. Pengadilan Tata Usaha Negara Manado harus lebih teliti lagi dalam perhitungan PPh Pasal 22 dan harus sesuai dengan peraturan yang ada.

2. Pengadilan Tata Usaha Negara Manado harus membayarkan langsung PPh Pasal 22 yang telah dipungut sesuai dengan peraturan yang ada. 


\section{DAFTAR PUSTAKA}

Avi-Yonah, Reuven S. 2013. International Tax As International Law. Vol. 57. Pages 483501.

Azis, A. Rifandi Abdul dan Novi Budiarso. 2016. Jurnal EMBA “Analisis Pemunggutan dan Pelaporan Pajak PPh Pasal 22 atas Kegiatan Impor Barang pada Kantor Pelayanan dan Pengawasan Bea dan Cukai Kota Manado”. Vol. 4. Hal. 753-762

Fleischer, Victor. 2014. Taxing Partnership Profits In Private Equity Funds. Vol. 83. Pages $1-59$

Gideon, Zhou dan Madhikeni Alouis. 2013. Systems, processed and challenges of public revenue collection $n$ in Zimbabwe. Vol.3. Pages 152-161

Gilson, Ronald J. and David M. Schizer. 2014. A Tax Explanation for Convertible Preferred Stock. Vol. 116. Pages 874-916

Hanlon, Michelle. 2013. A Review of Tax Research. Vol.50. Pages 127-178

Hidayah, Iftitahul dan Adi Listiono. 2014. Jurnal ABPI "Perhitungan PPN dan PPh Pasal 22 atas pengadaan alat kesehatan / Badan Peralatan Kesehatan Laboratorium / Radiologi pada Dinas Kesehatan Provinsi Jawa Tengah Tahun 2013”. Vol. 23. Hal. 50-67

Kasim, Chindy V.L. 2016. Jurnal EMBA "Perhitungan, Pemungutan dan Penyetoran Pajak pengahasilan (PPh) Pasal 22 Atas Belanja Barang Pada Korem 131 Santiago Manado. Universitas Sam Ratulangi Manado, Sulawesi Utara”. Vol. 4. Hal. 546-557

Mansor, Nor Hafizah Abdul. 2013. Goods and Services Tax (GST): A New Tax Reform in Malaysia. Vol.2. Pages 13-19

Mardiasmo. 2016. Perpajakan. Edisi Revisi. Penerbit Andi. Yogyakarta.

Murti, Hangga.W, Jullie J. Sondakh, Harijanto Sabijono. 2014. Jurnal EMBA "Pelayanan Fiskus dan Pengetahuan Perpajakan Terhadap Kepatuhan Wajib Pajak Orang Pribadi di Kota Manado. Vol. 2. Hal. 389-398

Pajak, Direktorat Jenderal. 2016. Bendahara Mahir Pajak. Direktorat Jenderal Pajak. Jakarta.

Peraturan Menteri Keuangan Republik Indonesia No. 107/PMK.010/2015

Peraturan Direktur Jenderal Perbendaharaan No. PER-3/PB/2014

Peraturan Menteri Keuangan No. 242/PMK.03/2014

Peraturan Menteri Keuangan No. 243/PMK.03/2014

Priyati, Novi. 2013. Pengantar Akuntansi. Penerbit Indeks. Jakarta.

Pura, Rahman. 2013. Pengantar Akuntansi 1. Penerbit Erlangga. Jakarta

Puspitha, P. Vilia, 2015. Analisis Pemungutan Pajak Penghasilan Pasal 22 Atas Kegiatan Impor Barang Pada Kantor Pengawasan Dan Pelayanan Bea Dan Cukai Tipe Madya Pabean Ngurah Rai

Saputri, D. Dwi, Siti Khairani, Ricardo Parlindungan, 2015. Perhitungan dan Pelaporan Pajak Penghasilan Pasal 22 Atas Pengadaan Barang di Kantor Badan Diklat Provinsi Sumatera Selatan

Sumarsan, Thomas. 2015. Perpajakan Indonesia. Penerbit Indeks. Jakarta.

Suwardjono. 2016. Akuntansi Pengantar. Yogyakarta: BPFE-Yogyakarta.

Sorongan, Clifvan T. 2014. Jurnal EMBA "Perhitungan dan pelaporan pajak penghasilan pasal 22 atas pengadaan barang pada Kantor Pelayanan Perbendaharaan Negara Kota Bitung. Vol. 2. Hal. 704-714

Tarigan, M. Ervan Rizky. 2015. Jurnal EMBA "Perhitungan dan pelaporan pajak penghasilan pasal 22 atas pengadaan barang pada Kantor Badan Perencanaan Pembangunan Penanaman Modal dan statistik Daerah Kabupaten Bolaang Mongondow". Vol. 15. Hal. 152-167

Waluyo. 2016. Perpajakan Indonesia. Penerbit Salemba Empat. Jakarta 